\title{
Opinions of occupational therapists on the positioning of vocational rehabilitation services in Gauteng Public Healthcare
}

\author{
Hester M van Biljon, B Occ Ther (UFS), M Occ Ther (UFS) \\ Work-link vocational rehabilitation practice. PhD candidate, University of the Witwatersrand, Faculty of Health Sciences, School of \\ Therapeutic Sciences, Occupational Therapy Department \\ Daleen Casteljien, BOT (Pret), BOT (Hons) (Medunsa), Dip Voc Rehab (Pret), DHETP (Pret), MOT (Pret),
PhD (Pret)
Associate Professor, University of the Witwatersrand, Faculty of Health Sciences, School of Therapeutic Sciences, Occupational \\ Therapy Department
}

Sanetta H J du Toit, BOT (UFS), MOT (UFS), M.Sc. OT (University of Exeter, UK), PhD (UFS) Affiliated lecturer, University of the Free State, Department of Occupational Therapy; Lecturer, University of Sydney, Faculty of Health Sciences, Discipline of Occupational Therapy

Lynn Soulsby, BSc OT (Wits)

Assistant Director, Occupational Therapy Department, Chris Hani Baragwanath Academic Hospital Johannesburg

Introduction: A collaborative effort to transform occupational therapist's vocational rehabilitation services in Gauteng's public healthcare was hampered by the fact that role players were unclear as to what the scope of the service should be within the various sectors and staffing levels of public healthcare. This article reports on the opinions of occupational therapists on the positioning of vocational rehabilitation services in the Gauteng Province.

Method: A collaborative action research team launched a non-experimental descriptive inquiry within the planning phase of a larger transformative project. Data were generated through an opinion survey to capture the perspectives of occupational therapists on the potential positioning of vocational rehabilitation services in the province. The opinions of three groups of occupational therapists were collected, i.e. clinicians working in Gauteng public healthcare, experienced vocational rehabilitation practitioners from all fields of service delivery who acted as critical friends and occupational therapy academia.

Results: The purposive sample was composed of 307 potential respondents. A low response rate of $31 \%$ was achieved. There was a lack of consensus as to which vocational rehabilitation services occupational therapists should render in public health care. The results reflected the need to address the scope and position of vocational rehabilitation services in public health care.

Conclusion: Positioning of vocational rehabilitation services in public health care remains a point of contention. However, the process of asking occupational therapists their opinion created awareness and directed continuous efforts to address the issues within the field of practice.

Key words: occupational therapy, vocational rehabilitation services, public healthcare action research, opinion survey

\section{INTRODUCTION}

In vocational rehabilitation occupational therapists focus on the human occupation of work, using their knowledge of pathology, ability to analyse activity and concern with occupational performance and purposeful activity'. The profession views the occupation of work as an integral part of their treatment process and a planned outcome of rehabilitation ${ }^{2-4}$. Occupational therapy's vocational rehabilitation services can be offered in and outside of healthcare facilities. Within healthcare facilities they assist with the transition from injury or illness, to return to optimal performance in work. Healthcare is often the first port of call for injured or sick workers and early intervention is an important indicator for successful return to work $^{5}$. Within a healthcare facility, occupational therapists are frequently the team members that identify and promote the need to address the work of a patient as part of the holistic management of his/her pathology ${ }^{6}$.

Occupational therapy vocational rehabilitation practices tra- ditionally offer a variety of services that can be found at various levels of healthcare ${ }^{7}$. Literature notes that vocational rehabilitation services offered by occupational therapists are not demarcated and grouped ${ }^{8}$ and that the categorising of healthcare facilities is a challenging exercise ${ }^{9}$. This double conundrum could be contributing to the difficulties of organising and managing the vocational rehabilitation services that occupational therapists offer in public healthcare facilities in Gauteng. In South Africa, $68 \%$ of the population depends entirely on public healthcare ${ }^{10}$ and injured or sick workers who fall within this group, can only access occupational therapy services through the various public healthcare facilities. With the restructuring of public healthcare to meet the constitutional ideals of a democratic South Africa, occupational therapy's vocational rehabilitation services in public healthcare became an unfortunate casualty. In Gauteng, these services appeared to have fallen into disarray.

In 20 I I the Assistant Director of Therapeutic and Medical Sup- 
port Services in Gauteng Health Department assembled a vocational rehabilitation task team (VRTT) to address vocational rehabilitation service problems in the province. In 2013 a PhD student, the first author, joined the VRTT as a member, with a research study titled: Transforming the vocational rehabilitation services of occupational therapy in Gauteng's public healthcare through action research. She had worked in and managed a public healthcare work unit in the 1980's and 1990's and retained a concern for and an awareness of the potential of vocational rehabilitation services in public healthcare.

The PhD study consisted of four phases. The first phase was observational in nature. The vocational rehabilitation practices offered by occupational therapists in Gauteng public health care, were observed. The second was a planning phase. The third phase was the implementation of multiple action research cycles to address specifically identified practice problems. The final phase was a meta-reflection on all previous phases, actions and practice transformation.

This article reports on part of phase two of the $\mathrm{PhD}$ study i.e. the need for a collaborative action plan that indicates what vocational rehabilitation services occupational therapists are and should be offering at the various healthcare facilities in Gauteng. The results would allow systematic and quantifiable actions such as addressing service delivery problems; managing resource distribution; organising personnel training; mentoring and support; as well as synchronising and coordinating service delivery to transform the service.

Multiple discussions about what vocational rehabilitation services occupational therapists should be offering at the various public healthcare facilities were held within the VRTT. The VRTT tasked the researcher to expand the discussion to public healthcare managers on hospital, regional and national level. The outcome of these discussions showed that previous attempts to address the question were not evidence based and had not filtered through to frontline clinical practice. During an interview with the Deputy Director: Disabilities in South Africa, it was agreed that there was no official demarcation of the vocational rehabilitation services that occupational therapist should be offering in public healthcare. He suggested that the occupational therapists that are, and should be, offering the services be asked for their opinion on the matter.

This democratic management approach of involving practitioners in the decision making process of their practice, is a fundamental characteristic of action research" ${ }^{\prime}$. It allows for the development of empowerment and ownership features in practitioners and is beneficial in the transformation of professional practice ${ }^{12}$. Developing an opinion survey and circulating it to all occupational therapists working in Gauteng's public healthcare was discussed in the VRTT. There was unanimous support for the idea and members volunteered to be involved at all stages of the inquiry; designing the opinion survey, distribution and gathering the survey responses, analysing data, critical reflection on the process as a whole and the dissemination of the results in the form of a peer reviewed journal paper. To validate and strengthen the opinion of clinical occupational therapists, the VRTT felt that academic occupational therapists at the three universities in Gauteng and occupational therapists experienced in the field of vocational rehabilitation should also be asked for their opinions. The latter group of occupational therapists had already been co-opted as critical friends for the $\mathrm{PhD}$ study.

For the purpose of the opinion survey, vocational rehabilitation services and healthcare facilities were each categorised into six groups.

\section{Types of vocational rehabilitation services offered by occupational therapists}

In her research Buys ${ }^{8}$ identified professional competencies occupational therapists need for delivering vocational rehabilitation services. She groups the competencies into aspects associated with types of services namely Prevention, Assessment, Intervention and Placement. These groupings were used in this research with two additional service groupings, Screening and Follow-up, that were practiced within the Gauteng public healthcare's practices.

Prevention is an educative service for the prevention of injury at work and to create an awareness of good work practice, averting the development and/or exacerbation of pathology ${ }^{13}$. Such services could include back programmes and spinal care education ${ }^{14}$, ergonomics $^{15}$, stress management ${ }^{16}$, energy conservation ${ }^{8}$ and the teaching of precautionary measures related to joint care and spinal hygiene ${ }^{17,18}$.

Screening of general or specific work related skills is a short prescriptive process used to filter and effectively refer patients to more specialised therapists or facilities ${ }^{19}$ and supports efficient service delivery. Examples of screening services currently in use in Gauteng's public healthcare would be screening of ability to work ${ }^{20}$ or ability to drive.

Assessment services involve the assessment of the ability of a person who has an injury or illness's, to be able to work and is a popular reason for referral to occupational therapy ${ }^{20,21}$. Such services would include work-place assessment ${ }^{22}$, functional capacity evaluations $^{23}$, medico legal assessments ${ }^{24}$, pre-placement screening ${ }^{25}$ and disability determination ${ }^{26}$.

Intervention services are programmes aimed at correcting or compensating for ability to work deficits ${ }^{20,27}$. There are a variety of intervention programmes that can be offered to correct work deficits or improve work performance. This is important in successful and sustainable placement into the open labour market, sheltered or protected work environments. Examples of such services could be job modification ${ }^{8}$, case management ${ }^{28}$, pain management ${ }^{29}$, work hardening ${ }^{20}$, work preparation or readiness ${ }^{30,31}$ work visits ${ }^{8}$, work guidance $^{8}$, work-place accommodation ${ }^{25}$, work adaptation ${ }^{8}$, job seekers groups ${ }^{32}$, self-employment initiatives ${ }^{8}$, support groups ${ }^{33}$ and other return to work efforts ${ }^{8}$.

Placement services are the returning of patients to their own, alternative or new work in the open labour market; or to sheltered - or protected workshops ${ }^{20,34}$. Work site visits would be essential with for example services such as job analysis ${ }^{35}$, accessibility and ergonomic audits ${ }^{36}$. Additional placement services would be vocational guidance and counselling ${ }^{37}$, outpatient support groups ${ }^{37}$, job acquainting ${ }^{8}$, adaptation and accommodation efforts and the redesigning of architectural barriers ${ }^{38}$.

Follow up is done of patients who used the services offered ${ }^{20}$. This could be with employers, referral sources, family members and the patients themselves. It could be done telephonically, electronically or during physical work visits ${ }^{26}$. The follow up of users of the vocational rehabilitation services demonstrates the occupational therapist's commitment to a case and conclude a comprehensive service. This service is fundamental to a sustainable and successful outcome.

Screening, follow-up and some of the intervention services can be offered by newly qualified occupational therapists, with no special skills or knowledge, but who have been orientated to the relevant protocols. No tools, equipment or venues other than what is available in a generic and basic occupational therapy department are required. Such services could be offered as regular programmes or as the need arises. The therapists could occasionally be expected to do work site and resource visits.

Prevention, assessment, placement and some of the intervention services need to be offered by occupational therapists with experience of a wide variety of pathologies ${ }^{24}$, good clinical reasoning skills and specialised knowledge and skills of work assessment and the labour market ${ }^{8}$. The use of standardised assessment tools and activities within a designated work area, work site visits and resource visits would be necessary.

\section{Public healthcare facilities in South Africa}

The South African National Health Act $^{39}$ specifies district, regional, central and specialised hospitals, with clinics for primary healthcare as categories of public hospitals. In this study these categories were used to group healthcare facilities. 
Clinics are facilities from which a range of primary healthcare services are provided to out-patients or ambulatory patients. The personnel who man these centres are focused on primary healthcare and are considered generalist in their professions. Clinics are normally open only 8 hours a day ${ }^{40}$.

Specialised hospitals have a maximum of 600 beds and provide specialised health services like psychiatric and rehabilitation services. Patients are seen on an in- or out-patient basis and the personnel specialises in the context of the hospitals service. Personnel is specialised in rehabilitative and related practices ${ }^{39}$.

District hospitals are 50 to 600 bed hospitals that serve a defined population within a health district and support primary health care. Such a facility provides 24 hour care services that include in-patient, out-patient and emergency health services. They could offer training for healthcare service providers. Their specialist services are limited and generally located at regional and central hospitals ${ }^{39}$.

Regional hospitals are 200 to 800 bed hospitals and serve a defined regional population, limited to provincial boundaries and receive referrals from district hospitals. They provide 24 hour care that includes in-patient, out-patient and emergency health services. They could provide training for healthcare service providers. They offer limited specialist services ${ }^{39}$.

Central hospitals, also known as tertiary hospitals are 400 to 1200 bed hospitals that provide a 24-hour care and a national referral service. They provide highly specialised units that require unique, highly skilled personnel. They must provide training for health care providers, conduct research and must be attached to a Health Science School or Faculty ${ }^{39}$.

An opinion survey was designed using the categories of vocational rehabilitation services and healthcare facilities as discussed above. Using this survey three groups of occupational therapists were asked their opinion on where to position these services in healthcare facilities.

\section{METHOD}

\section{Study design}

A multi-collaborative action research approach ${ }^{41}$ is the underlying phenomenology of the $\mathrm{PhD}$ project within which this inquiry is positioned. Although action research is popularly aligned with qualitative inquiry ${ }^{42}$ it is more correct to see it as a democratic and empowering approach to change ${ }^{12}$ that systematically draws on many ways of knowing, both qualitative and quantitative, in an iterative fashion ${ }^{43}$. The purpose of action research is to bring about change in a specific context ${ }^{44}$. Depending on the context and framework of the practice enquiry, action researchers use methods which best suit their purpose. The context of the practice problem associated with the uniqueness of the situation dictates the research tools and methods used ${ }^{4}$. Within healthcare is not uncommon to utilise quantitative data to complement qualitative data in action research projects ${ }^{12,41}$.

Action research places practitioners at the centre of an enquiry ${ }^{45}$ allowing them to be fellow researchers, planners and policy makers. Dick ${ }^{46}$ notes that plans provide the means by which the future can be influenced from the present and that if the planning is done collaboratively the journey of bringing about change is so much more efficient. A collaborative research team launched this non-experimental descriptive inquiry within the planning phase of a larger transformative action research project. The team needed a cost effective study design that could systematically and objectively collect the opinions of a selected population of occupational therapists'. An opinion survey study design was selected.

\section{Population and Sample}

Dick ${ }^{47}$ uses the term stakeholders in action research to describe a population. He describes stakeholders as persons who have a stake in a project and who are affected by or are able to affect practical change. In the pursuit of transformation within a practice, local as well as expert knowledge is often harnessed. This could bring about a variety of insider-outsider ${ }^{48}$ collaborations. Insider stakeholders are regular members of the organisation where the research is being conducted and outsider stakeholders join the organisation or research collaboration temporarily for the purpose of a research project $^{49}$. In this research there are two groups of insider stakeholders and two groups of outsider stakeholders. All of them were used as consensus populations.

The one insider stakeholder group was the research collaboration; the VRTT and a PhD student. The VRTT group consists of 14 occupational therapists, working in Gauteng's public healthcare sectors who are concerned with occupational therapy's vocational rehabilitation services in the province. The other three groups were the occupational therapists whose opinions were being surveyed. The first included the main insider stakeholder group, namely all occupational therapy clinicians working in Gauteng's public healthcare - a potential group of 242 stakeholders. The second, a pre-determined population sample, were a group of outsider stakeholders. They were 26 occupational therapists working as academics at the three universities situated within Gauteng; the University of the Witwatersrand, the University of Pretoria and the Sefako Makgatho Health Sciences University. The aim was to collect opinions from all occupational therapy academics at the three training institutions in Gauteng. The third pre-determined population sample was also outsider stakeholders. A group of 39 pre-selected vocational rehabilitation experts identified by the first author for use as critical friends in her $\mathrm{PhD}$. In action research the concept of critical friends is used to indicate stakeholders who are invested in the field of knowledge and can offer objective and expert feedback ${ }^{50}$. The criteria for inclusion into this group the participants had to be occupational therapists with previous experience of working in South Africa's public healthcare system and current experience of more than five years working in vocational rehabilitation.

\section{Data Collection Tool: The Opinion Survey}

The opinions of all the stakeholders were gathered in the form of a two page survey that was completed anonymously. The first author designed a draft survey. The VRTT and the first author's $\mathrm{PhD}$ support group critically reflected on it and gave feedback for improvement. Suggestions were incorporated, the survey was finalised, language edited and made available in electronic and hard copy format.

The first page of the opinion survey stated the research question. In a collegial letter format the reader was given the reason and background for the survey, the position of the survey within the larger study and what the responses would be used for. The ethical clearance number and the ethics committee contact details were supplied. Instructions were given on how to indicate opinions supported by an example. The return date for the survey was highlighted. All opinion surveys were to be returned to the first author. Four options for returning completed surveys were personal hand-back, facsimile, electronic or postal.

The second page of the opinion survey was headed by three demographic questions; place of work, number of years of experience in occupational therapy and in vocational rehabilitation. The six vocational rehabilitation services were placed in a column on the left side of the page with a brief definition and examples of the service. On the right side of the same page six options of the five public healthcare facilities and the option of none of the above was placed in a column with a brief description as well as examples of well-known facilities in Gauteng that qualify under the category. The respondent's opinion was indicated by drawing a line linking a vocational rehabilitation service with a healthcare facility where they felt it should be offered, giving a linear response. An open section for comments was provided at the end of the survey, providing opportunity for additional narrative responses (see Table I on page 48). 
Table I: Opinions of Occupational Therapists on the positioning of Vocational Rehabilitation Services in Gauteng's Public Healthcare Institutions

Where do you work?

How many years of practice do you have?

In Occupational Therapy: ___ years. In Vocational Rehabilitation:

years.

From your experience, and/or opinion match the Vocational Rehabilitation Services that should be offered at the various categories/ institutions of public healthcare in Gauteng?

\begin{tabular}{|c|c|}
\hline Vocational rehabilitation services & Public Hospitals/Healthcare Institutions \\
\hline $\begin{array}{c}\text { Prevention: } \\
\text { Programs for prevention of injury and aware- } \\
\text { ness of good work practice e.g. joint care, } \\
\text { spinal hygiene, ergonomics, and energy-saving } \\
\text { practices. }\end{array}$ & $\begin{array}{c}\text { Clinics: } \\
\text { e.g. Alexandra, Birchleigh, Sonto Tobela, } \\
\text { Zamani, Chiawelo, Crosby, Crown gardens, } \\
\text { Diepkloof, Nokupila, Eldorado Park, Boph- } \\
\text { elong, Jeppe, Lenasia, Malvern, Mofolo South, } \\
\text { Senoane, Polla Park, Itireleng, Westbury. }\end{array}$ \\
\hline $\begin{array}{l}\text { Screening: } \\
\text { Using the Vocational Rehabilitation Screening } \\
\text { Tool with the Modapts Work Samples guide. }\end{array}$ & $\begin{array}{l}\text { Specialized Hospitals: } \\
\text { e.g. Sterkfontein, Tara H Moross Center, }\end{array}$ \\
\hline \multirow{2}{*}{$\begin{array}{c}\text { Assessment } \\
\text { Assessing ability to work e.g. FCE's, Pilir, } \\
\text { Progress }\end{array}$} & Sizwe Tropical Disease \\
\hline & District Hospitals: \\
\hline \multirow{2}{*}{$\begin{array}{l}\text { Intervention: } \\
\text { Work hardening, readiness, preparation, } \\
\text { visits, guidance, accommodation, adaptation, } \\
\text { job seekers groups, self-employment initia- } \\
\text { tives, support groups. }\end{array}$} & Heidelberg, Germiston, Carletonville \\
\hline & $\begin{array}{c}\text { Regional Hospitals: } \\
\text { Kalafong, Coronation, Edenvale, Helen } \\
\text { Joseph, Tambo Meoriak, Far East Rand, Na- }\end{array}$ \\
\hline \multirow{2}{*}{$\begin{array}{l}\text { Placement: } \\
\text { Return to work (open labour market/shel- } \\
\text { tered/protected), Training and reskilling, sup- } \\
\text { port groups, guidance, counselling. }\end{array}$} & Dadoo, Sebokeng, Kopanong. \\
\hline & $\begin{array}{c}\text { Central/Tertiary Hospitals: } \\
\text { e.g. GaRankuwa (DGMAH), Pretoria (SBAH), } \\
\text { Soweto }(\mathrm{CHBAH}) \text {, Johannesburg (CMJAH) }\end{array}$ \\
\hline $\begin{array}{l}\text { Follow-up: } \\
\text { With clients/employers/referral sources in the } \\
\text { form of telephonic, electronic, home and/or } \\
\text { work visits. }\end{array}$ & $\begin{array}{l}\text { None of the above: } \\
\text { This service should not be offered by occupa- } \\
\text { tional therapists and/or should not be offered } \\
\text { in public healthcare and/or should not be } \\
\text { offered in the Department of Health. }\end{array}$ \\
\hline unave any adaitional quest & \\
\hline
\end{tabular}

\section{Data Collection}

The survey was distributed electronically and as hard copies by hand. Distribution and follow up was done by all members of the VRTT and the authors.

To maximise the response rate multiple distribution means were used. Emails were sent with a read receipt delivery option, the survey enclosed, a message explaining the inquiry and requesting assistance with distribution. This was sent to all members of the VRTT, the heads of occupational therapy departments in Gauteng public healthcare, the heads of department of the occupational therapy departments at the three universities in Gauteng and the individual emails of the vocational rehabilitation experts. VRTT members were given paper copies of the survey and asked to distribute them to the target population through all and any other opportunity that they could identify. Such forums were departmental meetings, interest groups, support groups, study groups, informal occupational therapy gatherings such as lunch breaks, continuing education and training workshops and regional and national occupational therapy forum meetings. Paper copies were also placed in the official personalised pigeon holes of all academic occupational therapists.

Additional follow-up was done by the VRTT members and the authors through telephonic and face to face awareness canvasing and promotion of the survey. Gauteng Health Head Office and management officially sanctioned the survey and contributed to follow up efforts through official channels.

The initial distribution was done from August 2014 to Novem- ber 2014. A disappointing response saw a repeat of the distribution effort from January 2015 to March 2015.

\section{Data analysis}

After the final due date responses were analysed and summarised. Frequencies for each possible combination (36 combinations in to$\mathrm{tal}$ ) in the linear responses were counted and presented in percentages. Consensus was determined if a certain percentage of votes for a specific combination fell within a prescribed range. These ranges were arbitrary decisions made by the authors. Percentages above $80 \%$ were viewed as strong consensus, between 70 and $79 \%$ as good consensus and between 60 and $69 \%$ as average consensus. Anything below $60 \%$ was viewed as inconclusive. Literature to support the authors' decision on the ranges of levels of consensus was scarce. Only one study by Hsu and Sandford ${ }^{51}$ briefly stated that consensus above $80 \%$ in opinion surveys by means of Delphi methods was good. These authors also mentioned that decisions on levels of consensus are situation-dependent and most of the time arbitrary.

The narrative responses were thematically categorised.

Results were shared at a VRTT meeting and kept for use in the planning phase of the larger research project.

\section{FINDINGS AND DISCUSSION}

Of the potential 307 occupational therapist identified, 96 responded, constituting a $31 \%$ response rate. This response rate is made up 


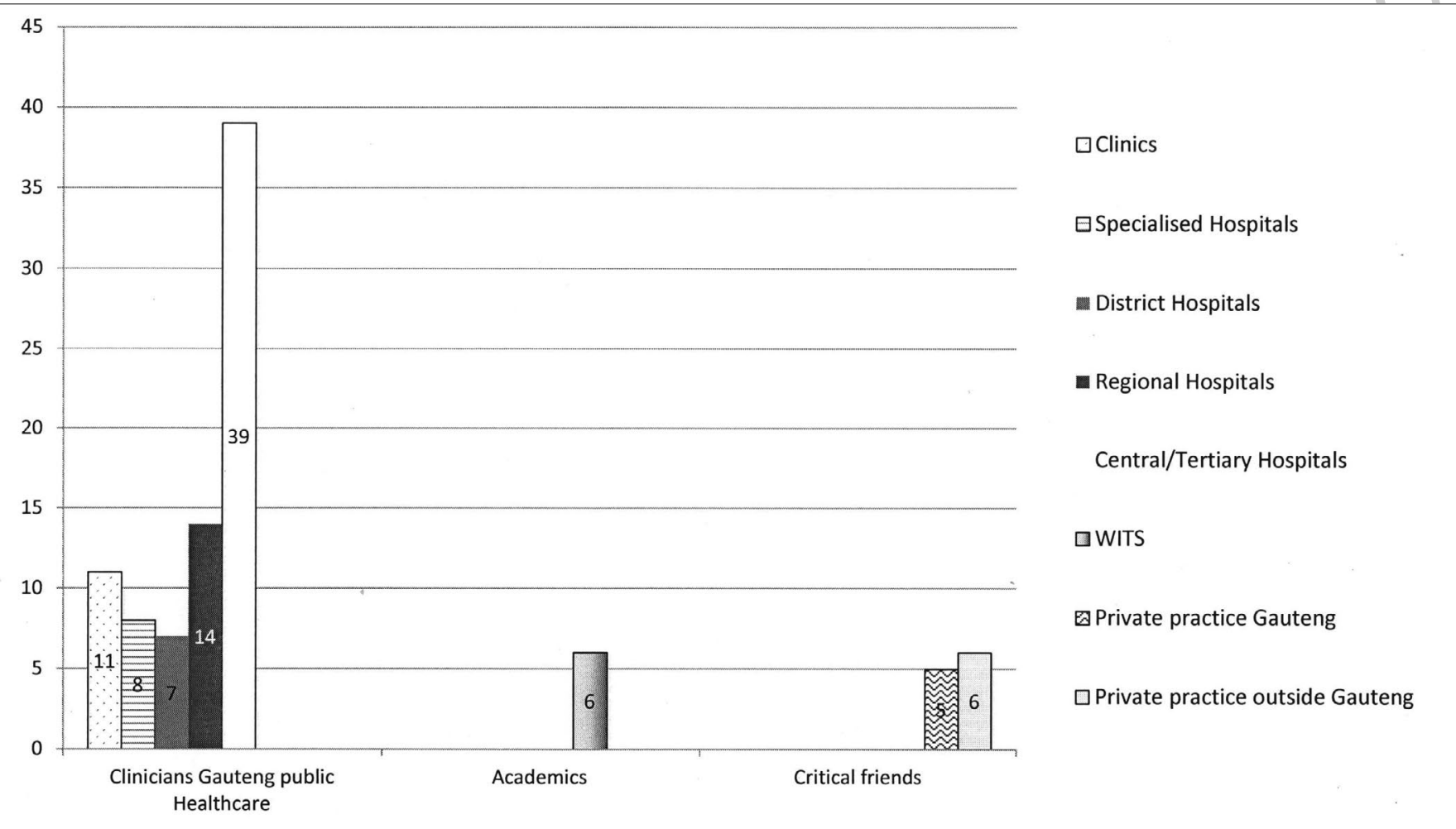

Figure I: Service sctor of respondents

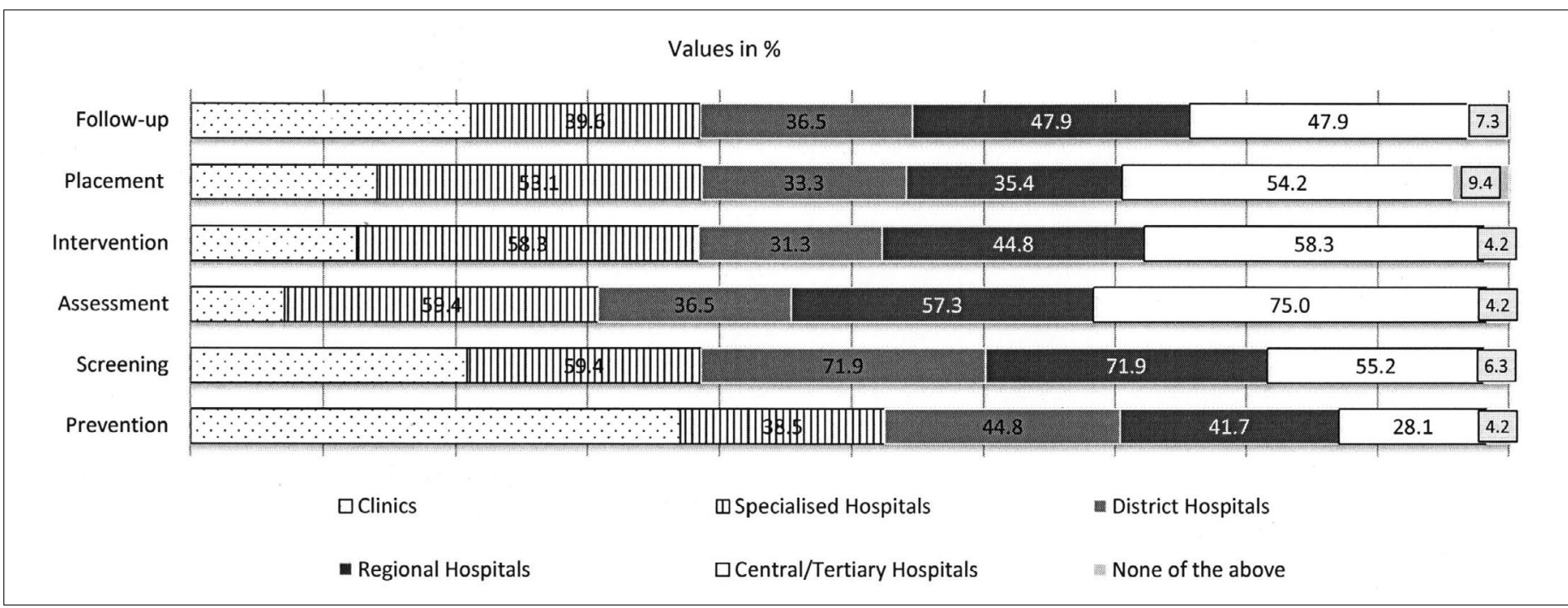

Figure 2: Opinions of clinicians, academics and critical friends of the positioning of vocational rehabilitation services in Gauteng Public Healthcare services

of $33 \%(n=79)$ occupational therapy clinicians working in public healthcare Gauteng, $28 \%(n=I I)$ critical friends and $23 \%(n=6)$ academics. Academic responses were received from only one training institution.

The service sectors of respondents is presented in Figure I: Service sector of respondents.

The linear responses were analysed for each group individually and for all respondents as a whole. The combined opinion of the three groups was rated from most preferred opinion to the least preferred opinion and displayed in Figure 2.

Response rate and demographic information: There is no agreed standard for an acceptable minimum response rate with mailed surveys, but a range from $30 \%$ to $80 \%$ is generally found ${ }^{52}$. This inquiry's response rate of $31 \%$ is at the bottom of the indicated general range. This nonresponse bias could be due to various reasons. Either occupational therapists do not have an opinion on the matter and did not make the effort to respond, or a lack of knowledge about the field of vocational rehabilitation and/or public healthcare could have prevented participation.

These assumptions are supported by the demographic results. In the case of the clinician and academic populations an average of two years' experience in vocational rehabilitation was found. The critical friends who were experts in vocational rehabilitation with an average of 10 years' experience in the field, had no current experience of working in Gauteng's public healthcare as they were mostly in private practice or worked outside Gauteng. They thus lacked knowledge of the various facilities and services offered in Gauteng's public healthcare.

Demographic information also revealed that the clinical occupational therapists with the most experience in vocational rehabilitation were working at clinics and those with the least experience were working in the central hospitals. At the time of the survey, work units with standardised and commercial vocational rehabilitation tests and equipment were located in central hospitals. Patients 
who needed more specialised vocational rehabilitation services were referred to these work units. The clinics offered only screening and supportive vocational rehabilitation services.

Linear responses: The three groups of survey respondents' were clinicians working in Gauteng's public healthcare, academics, and critical friends. The group with the most respondents was clinicians working in public healthcare. Of these respondents $49 \%$ $(n=39)$ were community service occupational therapists who have less than one year of experience in occupational therapy. Their responses showed that with the exception of prevention services done at clinics, assessment should be done at central hospitals and screening at all other facilities. Of interest was a lack of consensus on what vocational rehabilitation services specialised hospitals should be offering. By a significant margin the least chosen response was that no vocational rehabilitation services should be offered in public healthcare. This leads to the deduction that most clinicians are of the opinion that some form of vocational rehabilitation should happen at the various public healthcare facilities.

Additional consideration of clinicians' opinions showed that they felt clinics should be doing prevention, screening and follow up. District and regional hospitals should be doing prevention, screening and follow up. Central hospitals should be doing screening, assessment, intervention, placement and follow-up.

The academic opinion was from only one of the three universities and showed the lowest internal consensus, with no clear agreement of what services should be offered where. They were however unanimous in that none of them chose the option of "none of the above", indicating that they were of the opinion that all forms of vocational rehabilitation services should be done in public healthcare.

The other outsider group, critical friends, supported the opinion that vocational rehabilitation services should be done in public health care with one respondent being of the opinion that prevention and placement services should not be done in public healthcare. They felt that screening should happen at all facilities but most prominently at district and regional hospitals. In their opinion, assessment should be done at specialised hospitals and central hospitals. Interventions should be done at all facilities with the exception of district hospitals. Placement and follow up should happen at all facilities except at clinics.

The three groups agreed with each other on one point: Eightynine $(93 \%)$ indicated that preventative vocational rehabilitation services should be offered at clinics. Reflection on this strongly perceived opinion raises concern. Arguing from the premises that I) the aim of occupational therapy services should be to meet the needs of the clients that visit the facility where they work ${ }^{53,54}, 2$ ) the patient profile that visit public healthcare clinics is usually the elderly, the unemployed and mothers with babies or disabled children ${ }^{55,56} 3$ ) the nature of vocational rehabilitation prevention services are aimed at the prevention of injury at work and to create an awareness of good work practice, which implies that clients should be employed workers ${ }^{20,57}$. The conclusion must be drawn that the most strongly perceived opinion in this survey has been influenced by respondents' knowledge of the common clinical practice of prevention as part of primary healthcare at clinics. Respondents appeared unaware that prevention at clinic level would be an unsuitable option for vocational rehabilitation services within that setting.

A high level of consensus was that screening services should happen at clinics (70\%), district (72\%) and regional hospitals (72\%) and that assessments should be done at central hospitals (75\%). These opinions were reflective of the current state of affairs in Gauteng public health care facilities. There was no evidence of consensus about where intervention, placement and follow-up services should be offered. It is noteworthy that respondents reached consensus on only five of the $36(5 / 36)$ combinations of services and facilities and poor consensus (ranging between four and 59\%) for the rest of the combinations $(3 \mathrm{I} / 36)$.

Narrative responses: The option for narrative responses at the end of the survey was taken by $23 \%(n=72)$ of the respondents. The narrative responses showed three emergent themes of which the first two were contradictory. The contradictory themes, despite being in direct contrast with each other regarding practical implementation, deserve consideration as both schools of thought hold valid points.

The first theme indicated that all vocational rehabilitation services should be offered at all levels of healthcare and that all occupational therapists should be involved in offering such services. The suggestion was made that training of therapists, more equipment and more space should be considered by public healthcare management to ensure this. This opinion supports the constitutional right of equal access to health. It shows insight and consideration for the reality of public healthcare users when patients struggle to afford the out-of-pocket expenses associated with referral between healthcare facilities and other resources. It also addresses the sporadic problems of communication and service breakdown that occurs within the current referral system.

The second theme was that vocational rehabilitation is a specialised service that needs a multi-professional approach, dedicated posts, and implemented at a centralised location which is preferably not linked to healthcare. One strongly worded narrative indicated that vocational rehabilitation services cannot be categorised or separated. The opinion was that there should be a central work unit with a specialised multidisciplinary team attending to all aspects of vocational rehabilitation. Clinical experience in vocational rehabilitation services supports this opinion. Every patient that is seen has unique circumstances due to multiple variations of pathology and specific work requirements. This is further complicated by varying levels of prognosis, stages of recovery and availability of socio-economic resources. The result is that vocational rehabilitation services are often interlinked in clinical practice. Prevention services could for example be part of an intervention programme focused on returning to work.

The third theme identified current problems experienced with vocational rehabilitation services. These were mostly related to referral systems, problems with service efficiency and communication breakdown between healthcare facilities.

Both the linear and the narrative responses reflect the conflicting ideals and realities associated with vocational rehabilitation in public health. In order to provide affordable and accessible services to the majority of the South African population and to meet the rights of citizens, integrated service delivery models should be considered. However, due to the complexity of cases, as identified specifically by the second and third narrative themes, only highly trained and specialised staff with access to equipment and resources and to support multiple site visits, could deliver relevant outcomes. These contradictory expectations are evident within the linear responses.

Several factors had an impact on the trustworthiness of this inquiry. Respondents' varied levels of experience, competence and knowledge of vocational rehabilitation and the nature of public healthcare facilities could have negatively affected the credibility of the results. Practical challenges prevented the authors from presenting instructive workshops as an alternative to provide more detailed definitions of the various categories and using other data collection techniques like focus groups was not pursued.

Due to the unique focus of the inquiry into positioning of vocational rehabilitation services and its specific relevance for the Gauteng Public Health Care system, no research evidence could be accessed to support or contradict findings.

The trustworthiness of this inquiry was considered throughout by the authors. With deference to internal validity, the design and content of the opinion survey was standardised and critically reflected on by independent but concerned parties. All participants received the same survey form and reasonable attempts to avoid multiplications of a single respondent's opinion were done. Analysis of the results was done separately by the authors and then 
compared for final analysis. Purposeful transparency at all stages of the research was maintained by researchers and authors. Insider stakeholders were used as fellow researchers and were involved in all aspects of the research from the design of the opinion survey to the writing up of the results into a peer reviewed journal article. Objectivity was attended to by launching the inquiry, which is part of a PhD study, as an insider project through the VRTT. The survey population was made up of both insider and outsiders. Comparing the insider opinion results with two groups of outsider opinions through triangulation further enhanced the objectivity element. The aim of this survey was to use the emerging knowledge, occupational therapists opinion of where their vocational rehabilitation services should be offered, for future collaborative planning and policy making to improve the service. This brings about an important action research principle i.e. applying emerging knowledge within the population it was generated from.

\section{LIMITATIONS OF THE STUDY}

Subjective opinion, that which was gathered in this inquiry, is influenced by a vast variety of internal and external factors. This survey did not attempt to control any of these factors. The low response rate could also have affected the reliability of the results. These limitations can only be effectively attended to by a much larger scale of inquiry over a longer timeframe. Recognising this shortfall and planning for this deficit with the use of the data is important.

\section{CONCLUSION}

The results of this survey showed a general lack of consensus amongst occupational therapists about what vocational rehabilitation services should be offered at the different levels of public healthcare. With singular exceptions the generic opinion was that occupational therapy's vocational rehabilitation services should be offered in public healthcare. No other opinions from this survey give guidance or insight to support planning and policy making.

Therefore, this research cannot be used in isolation to inform planning and decision making regarding the positioning of vocational rehabilitation services in Gauteng public healthcare. It could be used in combination with other sources of information as part of an informed decision making process. A systematic review of international literature on where occupational therapists are delivering vocational rehabilitation services is suggested.

The benefit of this study does not lie in the content of the opinion survey. It lies in the nature of the inquiry, namely that frontline occupational therapists were asked for their opinion on matters which will affect their service delivery in future. This approach constructs a collaborative relationship for future efforts to identify and address problems with vocational rehabilitation services in Gauteng public healthcare. It raised a general awareness of vocational rehabilitation, informed practitioners of a broader perspective of service problems and allowed them to be included in planning and decision making efforts to address these. Continuous transparency, keeping all practitioners involved and informed, will maintain this sentiment and collective energy for future transformational efforts.

\section{ACKNOWLEDGEMENTS}

The authors wish to acknowledge co-researchers and members of the Vocational Rehabilitation Task Team, Gauteng: July Masango, Marlene Robus, Mariaan Jacklin, Siposethu Nxumalo, Alta Vorster, Buhle Moleofane, Claudette Parkinson, Madidimalo Mogale, Simon Rabothata, Mashudu Mphohoni, Naazneen Ebrahim, Zakkiya Akhalwaya. Maluta Tshivhase, Deputy Director: Disability, South Africa; Simon Rabothata, Deputy Director of Rehabilitation in Gauteng.

Thank you to all the occupational therapists, insiders and outsiders, who responded to the survey and took time to note their opinions.

The first author's PhD support group at the University of the Witwatersrand: Margot Graham, Lyndsay Koch, Tania Buys, Lizelle Jacobs, and Jennie McAdam are also acknowledged.

\section{REFERENCES}

I. Reed K, Sanderson S. Concepts of Occupational Therapy: Lippincott Williams \& Wilkinson, 1999.

2. Jacobs K. Occupational Therapy. Work Related programs and Assessments. Boston: Little, Brown and Company, 1991.

3. Pratt J, Jacobs K. Work Practice. International Perspectives. Oxford: Butterworth Heinemann, 1997.

4. du Toit V. Patient Volition and Action in Occupational Therapy. Hillbrow: Vona \& Marie du Toit Foundation, I99I.

5. Ntsiea MV, van Aswegen $\mathrm{H}$, Olorunju S. Factors which are predictive of return to work after stroke. The South African Journal of Physiotherapy, 2013; Wits Special Edition.

6. Soeker MS, Van Rensburg V, Travill A. Are rehabilitation programmes enabling clients to return to work? Return to work perspectives of individuals with mild to moderate brain injury in South Africa. Work: A Journal of Prevention, Assessment and Rehabilitation, 20I 2; 43(2): $17 \mid-82$.

7. Coetzee Z. Re-conceptualising vocational rehabilitation services towards an inter-sectoral model. South African Journal of Occupational Therapy, 20II; 4 I (2): 32 - 6.

8. Buys TL. Professional Competencies Required by Occupational Therapists Delivering Work Practice Services to Workers with Disabilities in the South African Open Labour Market. Pretoria: University of Pretoria; 2006.

9. Chetty KS. An integrated analysis of health facilities in the nine provinces of South Africa. South African Medical Journal, 1995; 85(4).

10. Ataguba JEaA, J. Health care financing in South Africa: moving towards universal coverage. CME, 20I0; 28(2): 74 - 8.

II. Whitelaw S, Beattie A, Balogh R, Watson J. A Review of the Nature of Action Research. Welsh Assembly Government. , (2003).

12. Hart E, Bond M. Action Research for Health and Social Care: A Guide to Practice. Buckingham: Open University Press, 1995.

13. Pomaki G, Franche RL, Murray E, Khushrushahi N, Lampinen TM. Workplace-Based Work Disability Prevention Interventions for Workers with Common Mental Health Conditions: A Review of the Literature. Journal of Occupational Rehabilitation, 20I 2; 22(2): $182-95$.

14. Brewin J, Hazell A. How Successful are We at Getting our Clients Back to Work? The Results of an Audit. British Journal of Occupational Therapy, 2004; 67(4): I48 - 53.

15. Gainer RD. History of ergonomics and occupational therapy. Work, 2008; 31 : 5 - 9.

16. Koletsi M, Niersman A, van Busschbach JT, Catty J, Becker T, Burns T, et al. Working with mental health problems: clients' experiences of IPS, vocational rehabilitation and employment. Soc Psychiat Epidemiol, 2009; 44: 96I - 70. Epub Springer-Verlag 2009.

17. McFeely G. Health at Work: an analysis of Black's and Frost's independent review of sickness absence - what can occupational therapists offer? The British Journal of Occupational Therapy, 2012; 75(7): $343-5$.

18. Jundt J, King PM. Work rehabilitation programs: a 1997 survey. Work: A Journal of Prevention, Assessment and Rehabilitation, 1999; 12(2): $139-44$.

19. Vocational Rehabilitation Task Team. Occupational Therapy Vocational Ability Screening Tool. Health and Social Development, editor. Johannesburg: Gauteng Province; 2013.

20. Buys T, van Biljon H. Occupational Therapy in Occupational Health and Safety: Dealing with Disability in the Work Place. Occupational Health, 1998; 4(5).

21. Gibson L, Strong J. A conceptual framework of functional capacity evaluation for occupational therapy in work rehabilitation. Australian Occupational Therapy Journal, 200I; 50: 64 - 7I.

22. Soderberg S, Jumisko E, Gard G. Clients' experiences of a work rehabilitation process. Disability and Rehabilitation, 2004; 26(7): 419-24.

23. Campbell TD, editor. Functional Capacity Evaluation (FCE) - Justifying, selecting and using assessments. occrehabltd@gmailcom; 2013; Occupational Therapy Department, University of the Witwatersrand: Campbell.

24. van Biljon HM. Occupational Therapists in Medico-Legal Work South African Experiences and Opinions. South African Journal of Occupational Therapy, 2013; 43(2): 27-33. 
25. Durand MJ. Therapeutic Return to Work: Rehabilitation in the workplace. Work, 200I; 17: 57 - 63.

26. Buys TL, van Biljon HM. Functional Capacity Evaluation: An Essential Component of South African Occupational Therapy Work Practice Services. Work, 2007; 29: 31-6.

27. Sturesson $M$, Edlund $C$, Fjellman-Wiklund $A$, Falkdal $A H$, Bernspång B. Work ability as obscure, complex and unique: Views of Swedish occupational therapists and physicians. Work, 20।3; 48(I): II 17 - 28.

28. van Biljon H. Occupational Therapy, the New Labour Relations Act and Vocational Evaluation: A Case Study. South African Journal of Occupational Therapy, 1997; 27(I).

29. Antao L, Shaw L, Ollson K, Reen K, To F, Bossers A, et al. Chronic pain in episodic illness and its influence on work occupations: $A$ scoping review. Work, 2013; 44(I): II - 36.

30. Russo D, Innes E. An organizational case study of the case manager's role in a client's return-to-work programme in Australia. Occupational Therapy International, 2002; 9(I): 57-75.

31. Stergiou-Kita M, Rappolt S, Kirsh B, Shaw L. Evaluating Work Readiness following Acquired Brain Injury: Building a Shared Understanding. Canadian Journal of Occupational Therapy, 2009; 76 (4): 276-84.

32. Shaw L, Polatajko H. An application of the Occupation Competence Model to organizing factors associated with return to work. Canadian Journal of Occupational Therapy, 2002; 69: 158-67.

33. Abrahams O. Vocational Rehabilitation and Employment Support Programme in a Public Hospital Setting in South Africa. odetteabrahams@niohnhlsacza, 2013.

34. Chang ML. Description of a return-to-work occupational therapy programme for stroke rehabilitation in Singapore. Occupational Therapy International, 2008; I5(2): 87 - 99. Epub 5 March 2008.

35. Canelon MF. Job Site Analysis Facilitates Work Integration. American Journal of Occupational Therapy, 1995; 49(5): 46 I - 7.

36. Owens TR, Hoffmann GL, Kumar S. An ergonomic perspective on accommodation in accessibility for people with disability. Disability \& Rehabilitation, 1996; 18(8): 402 - 7.

37. Main L, Haig J. Occupational therapy and vocational rehabilitation: an audit of an outpatient occupational therapy service. British Journal of Occupational Therapy, 2006; 69(6): 288 - 92.

38. Shamberg S. Occupational therapy practitioner role in the implementation of worksite accomodations. Work: A Journal of Prevention, Assessment and Rehabilitation, 2005; 24(2): 185-94.

39. Republic of South Africa. National Health Act, 2003 Regulations relating to categories of hospitals, 185 (20I2).

40. Cullinan K. Health services in South Africa: A basic introduction. Health Management, 2006; 29(II).

4I. Koshy E, Koshy V, Waterman H. Action Research in Healthcare. London: SAGE Publications, $201 \mathrm{I}$.

42. Denzin NK, Lincoln YS. Strategies of Qualitative Inquiry: SAGE Publication, 2007.

43. Reason PAB, Bradbury H. Handbook of Action Research. London: SAGE Publications Ltd, 2007.

44. Stringer E. Action Research. Upper saddle River, NJ: Pearson, 2004.

45. McNiff J, Whitehead J. All you need to know about Action Research. London: SAGE Publications, 2006.

46. Dick B. Action Research and Evaluation On-line Course. Australia: www.aral.com.au/areol; 2013.

47. Dick B. Entry and Contracting. Action research and evaluation on-line. Australia: www.aral.com.au/areol; 2013.

48. Cassell C, Symon G. Essential Guide to Qualitative Methods in Organizational Research. London: Sage Publications, 2004.

49. Kenneally A. The lived experience of Insider Action Research in a local government setting. The 3rd National Local Government Researchers' Forum; 5-6 June 2013; Adelaide, South Australia.20I3.

50. Costa A, Kallick B. Through the lens of a critical friend. Educational Leadership, 1993; 5 I (2): 49-5I.

51. Hsu C, Sandford B. The Delphi Technique: Making Sense of Consensus. . Practical Assessment, Research \& Evaluation A peer-reviewed journal, 2007; I2(10): I-8.

52. Kielhofner G. Research in Occupational Therapy: Methods of Inquiry for Enhancing Practice. USA: F A Davis Company, 2006.

53. Wilkins S, Pollock N, Rochon S, Law M. Implementing ClientCentred Practice: Why is it so Difficult to Do? Canadian Journal of Occupational Therapy, 200 I; 68(2): 70-9.
54. Kielhofner G. Conceptual Foundations of Occupational Therapy Practice. Philadelphia: F A Davis Company, 2009.

55. Bennett J, Morris G, Elgoni A, Bowie C. The Primary Health Care Package for South Africa - a set of norms and standards, Pretoria: 2000

56. Wentzel S. The Role of a Clinic Manager in a Primary Health Care Setting University of South Africa 2008.

57. Stout $\mathrm{N}$, Linn $\mathrm{H}$. Occupational injury prevention research: progress and priorities. Injury Prevention, 2002; 8. 